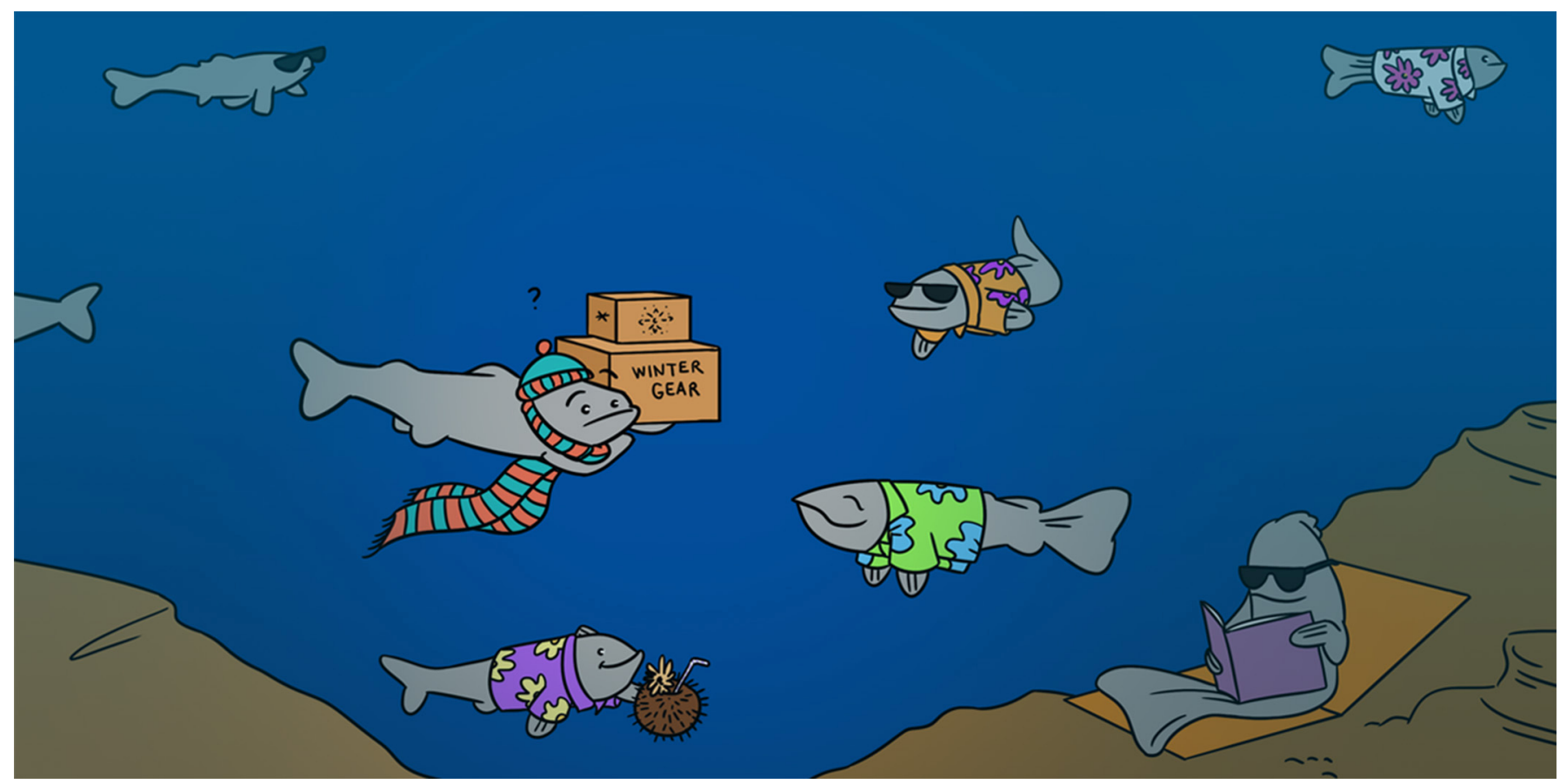

\title{
THE POLAR SEA ICE MELTS: WHAT HAPPENS TO THE FISH UNDER THE ICE?
}

\section{Leif Christian Stige *}

Department of Biosciences, Centre for Ecological and Evolutionary Synthesis, University of Oslo, Oslo, Norway

\section{YOUNG REVIEWER:}

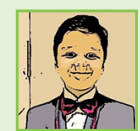

VARDHAN

AGE: 9

\section{POLAR COD}

A small fish species that lives in sea areas around the Arctic.
Imagine you are a fish, a polar cod, living in the ocean about halfway between Norway and the North Pole. In the old days, there used to be ice on the sea all winter. In summer, the ice melted. The melting of the ice marked the start of a hectic period with $24 \mathrm{~h}$ of daylight, plenty of food, and good conditions for building up your body fat reserves. In late fall, the sea surface froze again, very little light reached the sea, and it was time to rest and live on the fat reserves acquired during summer. In recent years, the sea water temperatures have risen, and a lot of the sea ice has melted. How have these changes influenced the polar cod and other creatures living in the oceans far north?

\section{THE POLAR COD-A TRUE ICE BATHER}

Did you know that sea water can be colder than $0^{\circ} \mathrm{C}\left(32^{\circ} \mathrm{F}\right)$ without freezing? While freshwater freezes at $0^{\circ} \mathrm{C}$, the salt in the sea water prevents the sea water from freezing until it reaches about $-2^{\circ} \mathrm{C}$. Fish that swim in such cold waters may, however, freeze and die. Only very hardy fish species can live in this environment. Polar cod (called Arctic 
Figure 1

Polar cod and its competitor, capelin The line shows the scale $(10 \mathrm{~cm}$ is $\sim 4$ inches). Photo: Leif Chr. Stige.

\section{PREY}

An organism that is killed and eaten by a predator.

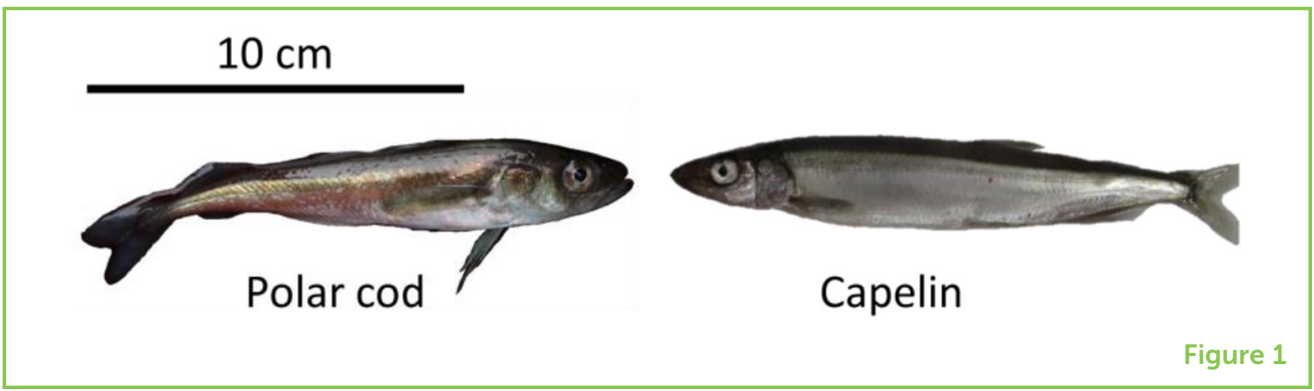

cod in America) is one such hardy species (Figure 1). Polar cod is a relative of the better-known cod that you may have heard of or even eaten, but is a different species. To handle the cold, the polar cod have anti-freeze chemicals in their blood, similar to the way people in cold countries pour anti-freeze into their car engines in winter. The warmer-water relatives of polar cod have no such anti-freeze chemicals, so they wisely avoid very cold waters.

\section{WHICH OCEAN AREAS ARE WE TALIKING ABOUT?}

Polar cod is one of the most numerous fish species in the northern Barents Sea [1]. The Barents Sea is part of the Arctic Ocean, which is the sea area north of Europe, Asia, and America, with the North Pole at its center (Figure 2). Sea ice covers the central parts of the Arctic Ocean all year-round. In areas farther south, the sea ice melts in summer and freezes again in fall. Even farther south, there is no sea ice at all. In recent decades, the temperatures on earth have risen due to human activities. As a result, much of the sea ice in the Arctic Ocean has melted. Many areas that were previously ice-covered year-round are now ice-free in summer, and many areas that were previously ice-covered in winter and ice-free in summer are now ice-free year-round [2]. One area where these changes are taking place is the Barents Sea.

\section{WHAT DID WE STUDY?}

The Barents Sea is the home of large populations of fish, seals, and other animals. Many fishing boats fish in the Barents Sea. Also, scientists regularly go into the Barents Sea on research ships, to find out how many fish are there and how many fish can be harvested by fishermen without depleting the populations. The research ships go on zig-zag routes across the ocean and count the fish along the way, using different kinds of fish-catching and fish-sensing equipment. The scientists calculate the total number of fish by assuming that fish occur in similar numbers between the zigzag tracks as along those tracks. The scientists also assess the living conditions of the fish: the temperature of the water, how much ice there is, and how many animals there are for the fish to eat (the fishes' prey). 


\section{Figure 2}

The location of the Barents Sea.

\section{Figure 3}

Who eats whom in the northern Barents Sea? A simplified food web of the Barents Sea, with arrows pointing from the key predators (those who eat), in this case capelin and polar cod, to their prey (those who are eaten).

\section{PREDATOR}

An animal that kills and eats individuals of other species.

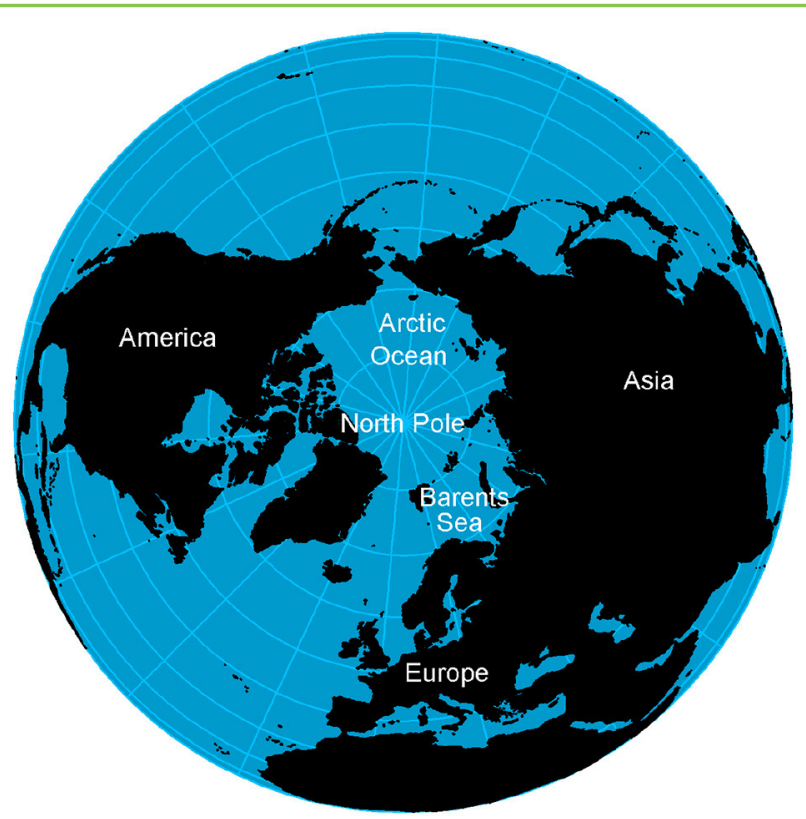

Figure 2

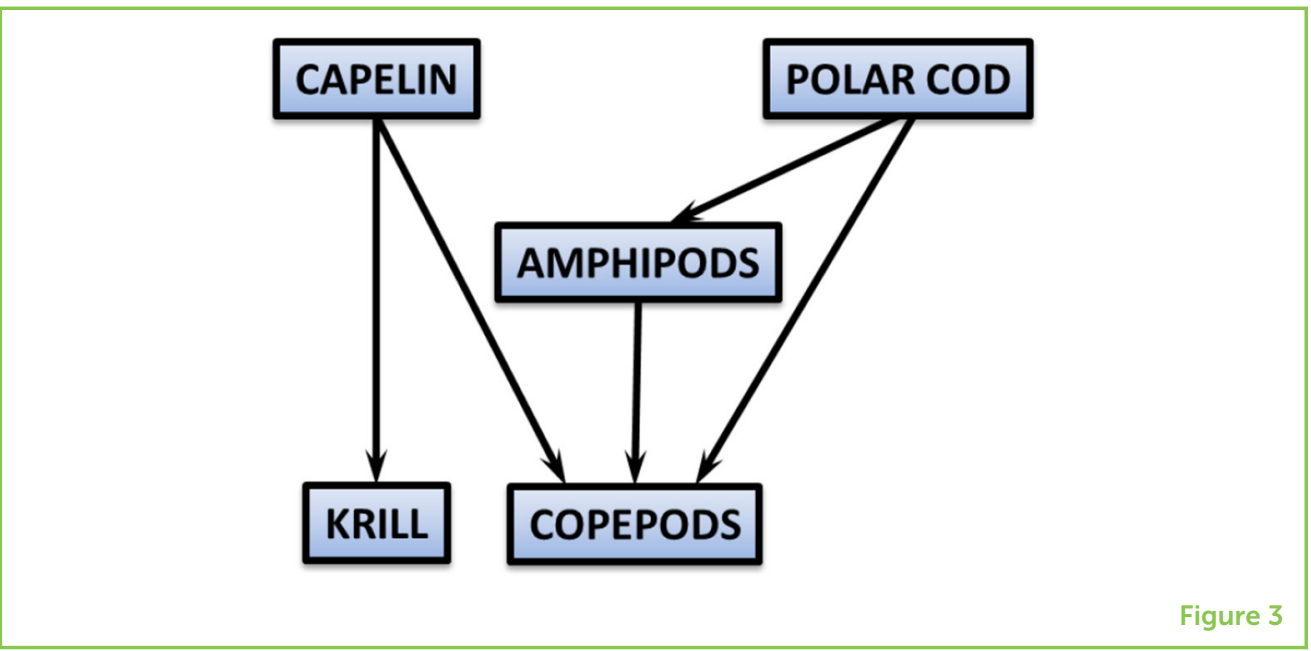

In a recent study, we analyzed some of these data, from the 1980s until now, to investigate how the changes in sea ice have affected the fish and their prey. Over this timespan, there have been many years with little sea ice, many years with lots of sea ice, and many years with intermediate amounts of sea ice. In our study, we compared how the numbers of individuals of different species of fish and their prey changed from 1 year to the next, depending on sea ice conditions and the numbers of individuals of each of the species (Figure 3 shows the food web of the organisms we studied).

\section{WHAT MAY HAPPEN TO THE POLAR COD IF THE SEA ICE DISAPPEARS?}

The young polar cod like to swim just under the ice and hide in crevices in the ice if their predators come along. The predators are animals that like to eat polar cod, and include other fish species, seals, and sea birds. 


\section{CAPELIN}

Another small fish species that competes with polar cod for food.

KRILL

Small shrimp-like animals with many legs. A key prey of capelin.
Polar cod, in turn, are predators of smaller animals, which we will come back to soon. What happens when the ice disappears? The young polar cod will have nowhere to hide from predators. There may also be more predators around, as higher temperatures allow less-hardy fish species to move in from the south-fish species that like to eat polar cod. On the other hand, decreased amounts of sea ice can also be good for the polar cod, because the spring arrives earlier and the polar cod have more time to swim around, eat, and build up body fat reserves for the winter. It is not obvious if the good effects or the bad effects of decreased sea ice are strongest. We were therefore curious whether the numbers of polar cod tended to increase or decrease in years with little sea ice. But, before revealing what we found for polar cod, let us consider some of its competitors and prey.

\section{THE CAPELIN-A LONG-DISTANCE MIGRANT}

Another fish species that visits the northern Barents Sea each summer is capelin [1,3]. In winter, the capelin swim to areas a bit farther south, where waters are not quite as cold as in the northern Barents Sea and the sea surface does not freeze. In summer, the capelin follow the retreating ice edge northwards, feeding on the plentiful prey organisms found in the waters where the sea ice has recently retreated. Capelin eat many of the same prey organisms that polar cod eat; capelin and polar cod are therefore competitors [4].

We found that the capelin population tended to grow in warm years with little sea ice, possibly because their feeding area was larger during these years. The ups and downs in the capelin population did not depend only on sea ice. It also depended on the numbers of prey and predators: not surprisingly, the capelin population increased the most in years with few predators and many prey. The main predator affecting the capelin was the cod (not the polar cod, but the relative without anti-freeze chemicals). The main prey affecting the capelin was krill.

\section{KRILL-"MINI-SHRIMPS"}

Krill look somewhat like miniature shrimps. Both krill and shrimps belong to a group of organisms called crustaceans, which have a hard shell and many legs. Krill have ten legs, which they use for swimming. Most krill species do not like very cold temperatures, and there are fewer krill in the northern Barents Sea than in the warmer waters to the south. In years with little sea ice, we found that the number of krill tended to increase in the northern Barents Sea, most likely because they drifted with the currents from the areas farther south.

For the krill, the benefit of a warm year with little sea ice appeared to be only short-term. As you may remember, the number of capelin also 
increased in warm years with little sea ice, and capelin eat krill. Hence, more krill were eaten by capelin for several years after a year with little sea ice, because there were more capelin around. In other words, the short-term effect of little sea ice on krill in the northern Barents Sea was good, but the long-term effect was bad.

\section{WHAT HAPPENED TO OTHER PREY ORGANISMS?}

We also looked into what happened to other small crustaceans that are prey of polar cod and capelin. In short, the main prey of polar cod were reduced in numbers during warm years with little sea ice.

\section{BACK TO THE POLAR COD}

To our surprise, we found no association between the ups and downs in the polar cod population and the sea ice conditions. The changes in the polar cod population also showed no relation to the numbers of polar cod's prey and predators. We therefore found no evidence for effects of sea ice on polar cod. This lack of association may mean that, so far, the polar cod has been tough enough to withstand the changes in sea ice, and that other factors besides the amount of sea ice have been more important for driving the changes in the polar cod population. Perhaps, so far, the good and bad effects of decreasing sea ice have canceled each other out? We do not know, and we plan to investigate this question in more detail in future studies.

\section{WHY ARE THESE FINDINGS IMPORTANT?}

Understanding how climate influences ecosystems is important for protecting species that are threatened by climate change and for adjusting human activities, such as fishing. For example, fish populations that grow and survive better in a warmer climate may tolerate more fishing in the future than today. Other fish populations may tolerate less fishing and become over depleted unless we reduce the fishing pressure.

By investigating the changes in all these species, we separated the direct and the indirect effects of sea ice changes on each species. By direct effects, we here mean the short-term effects, such as how a decreased amount of sea ice was good for krill in the short term because more krill drifted in from the south. By indirect effects, we mean the longer-term effects that happen through other species, such as how a decreased amount of sea ice was bad for the krill in the long-term, because the number of capelin increased. In fact, we found that the indirect effects were just as important as the direct effects. A take-home lesson from our study is that the indirect effects of climate 
change through other species may be just as important or even more important than the direct effects on species, such as polar cod.

The long-term fate of the polar cod in a warmer climate remains uncertain. The polar cod probably need sea ice to protect their young, which may force them to move northwards as the ocean temperature rises [5]. Whether the polar cod will thrive in the areas farther north depends not only on the sea ice, but also on what happens to their prey, competitors, and predators. By understanding these relationships, our research can help to protect the polar cod, and possibly other fish species, as the earth's climate continues to change.

\section{ACKNOWLEDGMENTS}

I thank the Research Council of Norway for funding through the Nansen Legacy project (RCN \# 276730) and Lena Seuthe, Yngvar Stige, Susan Debad, and a young referee for helpful comments on this manuscript.

\section{ORIGINAL SOURCE ARTICLE}

Stige, L. C., Eriksen, E., Dalpadado, D., and Ono, K. 2019. Direct and indirect effects of sea ice cover on major zooplankton groups and planktivorous fishes in the Barents Sea. ICES J. Mar. Sci. 76:i24-36. doi: 10.1093/icesjms/fsz063

\section{REFERENCES}

1. Hop, H., and Gjøsæter, H. 2013. Polar cod (Boreogadus saida) and capelin (Mallotus villosus) as key species in marine food webs of the Arctic and the Barents Sea. Mar. Biol. Res. 9:878-94. doi: 10.1080/17451000.2013.775458

2. Comiso, J. C., Meier, W. N., and Gersten, R. 2017. Variability and trends in the Arctic Sea ice cover: results from different techniques. J. Geophys. Res. Oceans 122:6883-900. doi: 10.1002/2017JC012768

3. Gjøsæter, H. 1998. The population biology and exploitation of capelin (Mallotus villosus) in the Barents Sea. Sarsia 83:453-96. doi: 10.1080/00364827.1998.10420445

4. Orlova, E. L., Dolgov, A. V., Rudneva, G. B., Oganin, I. A., and Konstantinova, L. L. 2009. Trophic relations of capelin Mallotus villosus and polar cod Boreogadus saida in the Barents Sea as a factor of impact on the ecosystem. Deep Sea Res. II 56:2054-67. doi: 10.1016/j.dsr2.2008.11.016

5. Hollowed, A. B., Planque, B., and Loeng, H. 2013. Potential movement of fish and shellfish stocks from the sub-Arctic to the Arctic Ocean. Fish. Oceanogr.

22:355-70. doi: 10.1111/fog.12027 
SUBMITTED: 18 October 2019; ACCEPTED: 09 June 2020;

PUBLISHED ONLINE: 15 July 2020.

EDITED BY: Christian März, University of Leeds, United Kingdom

CITATION: Stige LC (2020) The Polar Sea Ice Melts: What Happens to the Fish Under the Ice? Front. Young Minds 8:91. doi: 10.3389/frym.2020.00091

CONFLICT OF INTEREST: The author declares that the research was conducted in the absence of any commercial or financial relationships that could be construed as a potential conflict of interest.

COPYRIGHT () 2020 Stige. This is an open-access article distributed under the terms of the Creative Commons Attribution License (CC BY). The use, distribution or reproduction in other forums is permitted, provided the original author(s) and the copyright owner(s) are credited and that the original publication in this journal is cited, in accordance with accepted academic practice. No use, distribution or reproduction is permitted which does not comply with these terms.

\section{YOUNG REVIEWER}

\section{VARDHAN, AGE: 9}

My name is Vardhan and I am 8 years old. I enjoy cricket and reading books on outer space. My favorite subjects are Math and English.

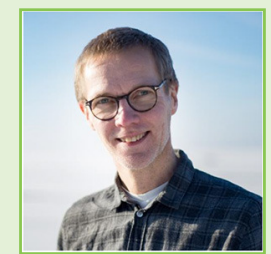

\section{AUTHOR}

\section{LEIF CHRISTIAN STIGE}

Leif Christian Stige has worked as researcher at the University of Oslo in Norway for more than 10 years. He investigates how changes in climate and human activities, such as fishing influence marine species. To do so, he analyses data collected over many years, to search for associations between changes in the fish populations and factors, such as climate conditions, other species, and fishing. He is also interested in how oil spills may affect the species in the ocean. Most of his research has been on the Barents Sea ecosystem. *l.c.stige@ibv.uio.no 